\title{
Acquisition of stimulus control of bar-press avoidance behavior with guinea pigs
}

C. D. WEBSTER AND MAXINE WALSH, ALCOHOLISM AND DRUG ADDICTION RESEARCII FOUNDATION, Toronto 4 , Ont., Canada

Guinea pigs were trained to hold a bar continuously during stimulus On and to release it during stimulus Off. The Ss for whom onset and offset of stimulus were made response contingent exhibited a higher level of discriminated avoidance and received fewer shocks than $S s$ for whom stimulus change occurred automatically.

Keehn \& Webster (1967) have shown that rats and guinea pigs can be trained to avoid shocks by pressing and holding a bar following the onset of a discriminative stimulus and by releasing the bar following the offset of the stimulus. With this procedure, animals received shocks at $5 \mathrm{sec}$ intervals unless they held the bar during the stimulus On (hold) condition and if they held during the stimulus off (release) condition. The rats were trained by alternating automatically $30 \mathrm{sec}$ periods of stimulus $\mathrm{On}$ and stimulus Off (i.e., the rats entered the stimulus On condition even when they held throughout the stimulus off condition, and similarly, they entered the Off condition even when they failed to depress the bar throughout the stimulus On condition). The guinea pigs were, however, trained with an alternative and possibly more effective procedure in which stimulus change was made response contingent. In the experiment described below the automatic and response-contingent stimulus-change procedures were compared.

Subjects. Four adult male guinea pigs about seven months old (weight range $800-900 \mathrm{~g}$ ) served as Ss. The animals were provided with food and water ad lib.

Apparatus. The experimental chamber was a Grason-Stadler two-bar rat box type E3125D. Bar 2 was removed. A weight of about $20 \mathrm{~g}$ on Bar 1 activated the automatic programming and recording equipment. Three $117 \mathrm{~V}$ $7 \mathrm{~W}$ stimulus lights were employed; green at the top center of the box, red above and slightly to the left of the bar, and white above and slightly to the right of the position normally occupied by Bar 1 . A $1000 \mathrm{cps}$ tone (at $82 \mathrm{~dB}$ ) was supplied from a Foringer multiple stimulus panel (Type 1166-4-M1).

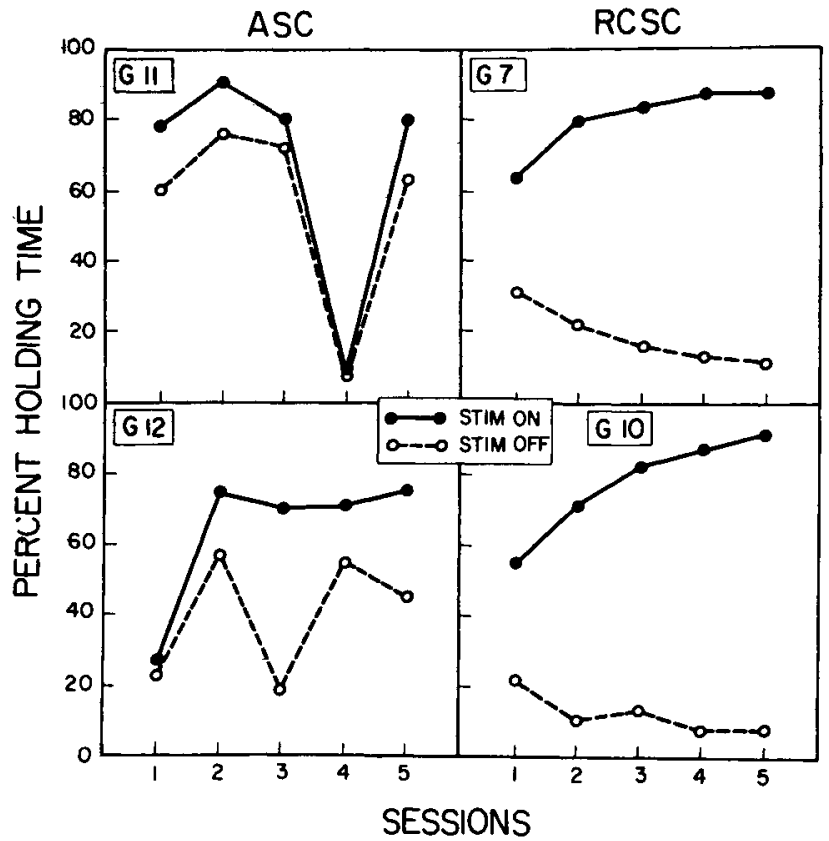

Fig. 1. Per cent of time each animal spent bar-holding during stimulus On and Off periods during Sessions 1 to 5 .
Scrambled shocks were supplied by a Grason-Stadler shock generator (Model E6070B) with intensity set at $2.0 \mathrm{~mA}$ and duration at $.5 \mathrm{sec}$.

Response records were obtained by making a Gerbrands cumulative recorder step once for about every $.2 \mathrm{sec}$ that the bar was held down. The experimental chamber was enclosed in a Grason-Stadler sound attenuating enclosure (Model No.E3125AA-3) which was located inside a closet in the experimental room.

Procedure. Two stimulus conditions were used. During one stimulus condition (On), consisting of red light, white light, and tone, shocks occurred every $5 \mathrm{sec}$ unless the bar was pressed and held for a period of time. Bar depression postponed shocks until $5 \mathrm{sec}$ after the bar was released. During the other stimulus condition (Off), consisting of a green light, shocks occurred every $5 \mathrm{sec}$ whenever the bar was held down for longer than $5 \mathrm{sec}$.

Two training procedures were used. With one of the procedures, periods of stimulus On and Off alternated automatically (ASC) every $30 \mathrm{sec}$. With the other procedure stimulus change was response contingent (RCSC); that is, stimulus On commenced only when the bar had been released continuously during the Off period for $30 \mathrm{sec}$, and the Off period began only when the bar had been held down continuously for $30 \mathrm{sec}$ during the On condition. Two Ss (G11 and G12) were trained with the ASC and two (G7 and G10) with the RCSC procedure.

All four guinea pigs were given two 30 -min preliminary bar-holding training sessions during which they were shaped to hold the bar during stimulus On. The guinea pigs then received either ASC or RCSC training for five discrimination-training sessions. Sessions were run daily and were $90 \mathrm{~min}$ long.

Results and Discussion. All four guinea pigs developed continuous, or almost continuous, bar-holding behavior during preliminary training. During the first discrimination-training session, the two ASC animals held the bar depressed during the Off condition for almost as long as they held it depressed during the On condition. On the other hand, the two RCSC animals held considerably less during the Off periods of the first session than during the On periods. This can be seen from Fig. 1 which shows, over sessions, the per cent of time which the two ACS and two RCSC guinea pigs held the bar during each of the two stimulus conditions. From the curves on the left it is evident that G11 and

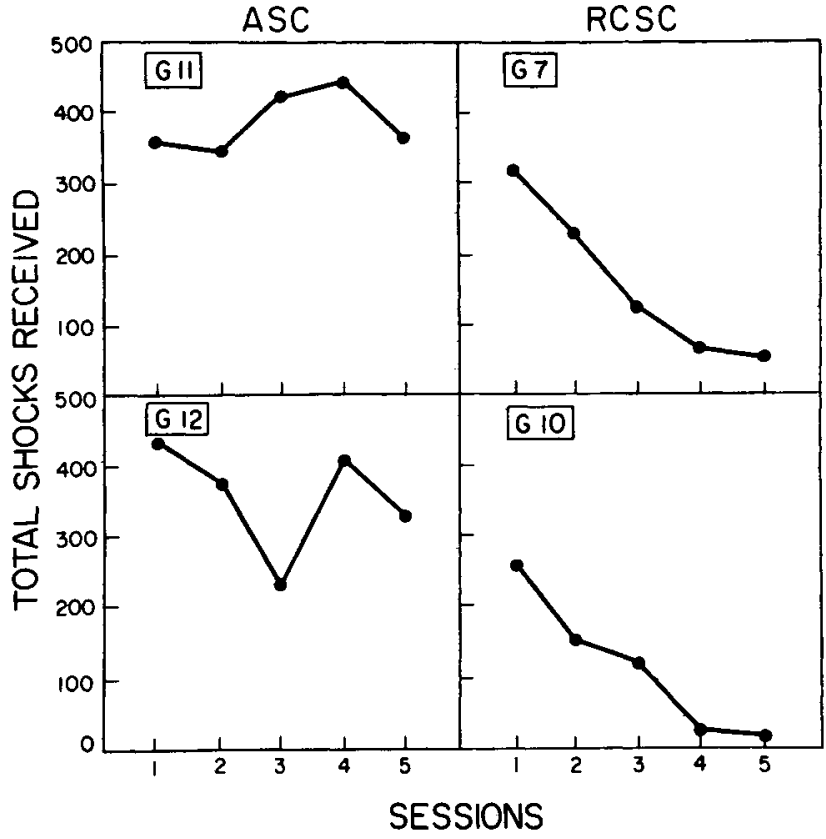

Fig. 2. Total number of shocks received by each animal during Sessions 1 to 5 . 


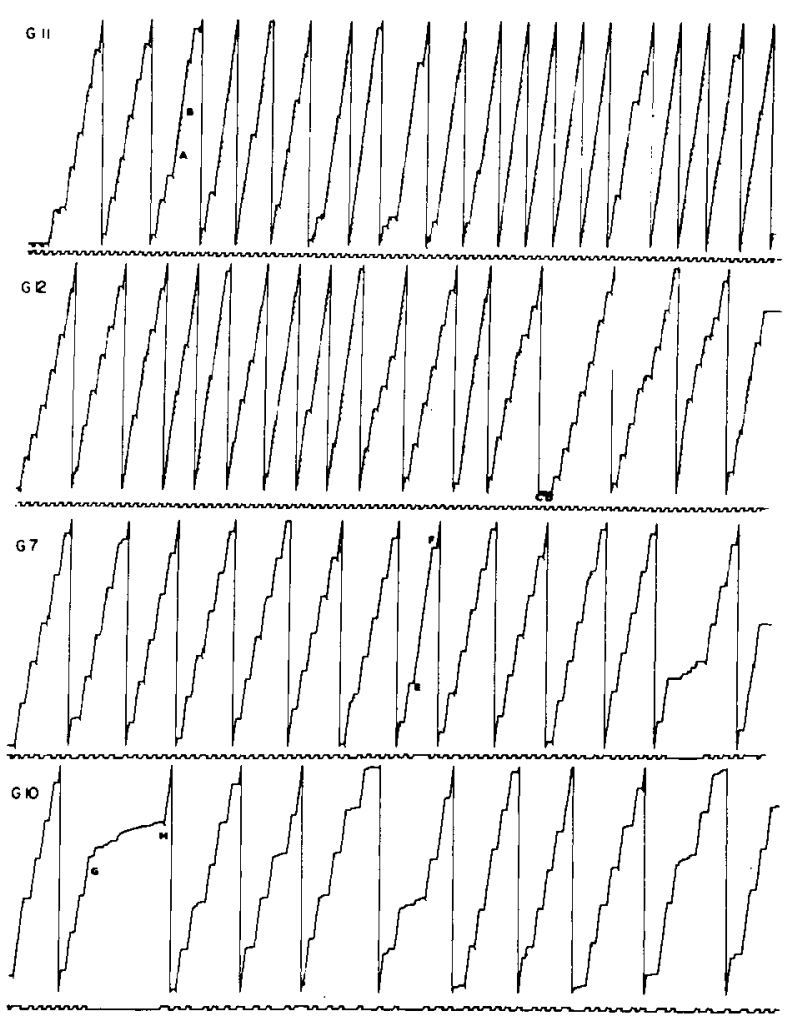

Fig. 3. Cumulative bar-holding records for each animal during Session 5 . A full excursion required approximately $200 \mathrm{sec}$ holding. The lower trace shows stimulus On (up) and Off (down).
G12 exhibited considerable variability in time spent holding during the On and Off conditions and that there was no systematic improvement in discrimination as training was extended. In contrast, the RCSC animals showed progressive increases in holding during the On condition and decreases during the Off period.

In Fig. 2 the ASC and RCSC Ss are compared in terms of number of shocks received. While the RCSC animals showed a systematic decrease in shocks received, no such decrease was evident in the case of the ASC animals. An animal in the ASC condition could receive 450 shocks in a $90 \mathrm{~min}$ session by continuous holding or releasing of the bar; G11 and $\mathrm{G} 12$ received almost this number of shocks during several of the sessions.

Individual records of all four Ss during Session 5 are shown in Fig. 3. The ASC animals tended to hold through the stimulus off condition (e.g., between A and B in Gll's record) and occasionally remained off the bar during the stimulus On condition (e.g., between C and D in G12's record). While for the most part, the RCSC guinea pigs avoided shocks by holding during the On period and remaining off the bar during the Off interval, they occasionally maintained the On condition longer than $30 \mathrm{sec}$ by releasing and re-pressing (e.g., between $E$ and F in G7's record), and they sometimes maintained the Off condition by pressing and releasing (e.g., between $\mathrm{G}$ and $\mathrm{H}$ in G10's record).

The results were clear in showing that while the acquisition of press and release avoidance was relatively rapid when stimulus change was response contingent, there was little or no evidence of the development of the appropriate discriminations when conditions were changed automatically. The superiority of the RCSC procedure over the ASC procedure may be attributed to the fact that, under the RCSC condition, the possibility of adventitious reinforcement was eliminated.

\section{REFERENCES}

KEEHN, J. D., \& WEBSTER, C. D. Acquisition and maintenance of barpress avoidance by rats and guinea pigs. Paper presented at the annual meeting of the Psychonomic Society, Chicago, 1967. 